\title{
Control of Brushless DC Motor with Ant Colony Optimization
}

\author{
FANG Yong-wang ${ }^{1, a}$, FANG Hong-wei ${ }^{2, b^{*}}$ and Xiong Mu-Feng ${ }^{2}$ \\ ${ }^{1}$ Hangzhou Gubei Electronics Technology Co. Ltd, Hangzhou Zhejiang 310053 China \\ ${ }^{2}$ School of Electrical Engineering and Automation, Tianjin University 300072 China \\ afriendfyw@163.com, bhongwei_fang@tju.edu.cn
}

Keywords: Brushless DC motor, ant colony optimization, load observer, elevator door.

Abstract. A novel speed servo control approach for the elevator door driving system is proposed to improve the performance. The control approach includes a current loop and a speed loop. The fuzzy logic controller is utilized in the speed loop, where the logic rules are designed and parameters are adjusted based on ant colony optimization (ACO). In the current loop, a hysteresis controller is used to limit the phase current with a preset hysteresis band. Moreover, a load torque observer is used to enhance the robustness against disturbances of the servo system with varying motor parameters and external load variation. The simulation and experimental results have shown the feasibility of the proposed control method.

\section{Introduction}

The advantages of a brushless DC motor include big starting torque, high efficiency, less electrical noise without sparkle, simple implementation, and low cost. Consequently, it has been widely used in many servo applications, such as aerospace, robotics, machine tools, electric vehicles, chemical industries, and so on [1]-[2]. Also, new advanced control algorithm and novel motor structure have been proposed to reduce the torque ripple, and enhance the servo control performance of the brushless DC motor in recent years [3]-[4]. The design of fuzzy Control of electrical motor has been optimized with neural networks, genetic algorithm (GA), ACO and other optimization algorithms to enhance the motor servo control system performance in many works [5]-[6].

In this paper, an ACO based fuzzy controller with a load observer is proposed for the sensorless control of the elevator door driven by the brushless DC motor. In contrast to the previous work [7], the speed reference model is abolished to reduce the cost and complexity of the system, and to lessen the effect from inaccurate modeling of the motor. A simple load observer is introduced to enhance the anti-disturbance ability of the control approach. The membership function of the fuzzy controller is optimized by a variant of the ACO algorithm.

\section{BLDCM Servo System}

Brushless DC motors are usually used to drive the elevator doors due to their low noises and high efficiencies. The sensorless control scheme for brushless DC motors makes the cost of the controller more competitive. Fig. 1 shows a typical elevator door control system through a brushless DC motor. The three phase voltage equations of the non-salient brushless DC motor can be represented in a matrix form as

$$
\left[\begin{array}{l}
u_{\mathrm{a}} \\
u_{\mathrm{b}} \\
u_{\mathrm{c}}
\end{array}\right]=\left[\begin{array}{ccc}
R & 0 & 0 \\
0 & R & 0 \\
0 & 0 & R
\end{array}\right]\left[\begin{array}{l}
i_{\mathrm{a}} \\
i_{\mathrm{b}} \\
i_{\mathrm{c}}
\end{array}\right]+\left[\begin{array}{ccc}
L-M & 0 & 0 \\
0 & L-M & 0 \\
0 & 0 & L-M
\end{array}\right] \mathrm{p}\left[\begin{array}{l}
i_{\mathrm{a}} \\
i_{\mathrm{b}} \\
i_{\mathrm{c}}
\end{array}\right]+\left[\begin{array}{c}
e_{\mathrm{a}} \\
e_{\mathrm{b}} \\
e_{\mathrm{c}}
\end{array}\right]
$$

where, $u_{\mathrm{a}}, u_{\mathrm{b}}$ and $u_{\mathrm{c}}$ are the stator phase voltages; $R$ is the phase winding resistance; $i_{\mathrm{a}}, i_{\mathrm{b}}$ and $i_{\mathrm{c}}$ are the line currents; $e_{\mathrm{a}}, e_{\mathrm{b}}$ and $e_{\mathrm{c}}$ are back EMFs; $L, M$ is the self and mutual inductance respectively; and $\mathrm{p}$ is the differential operator. 


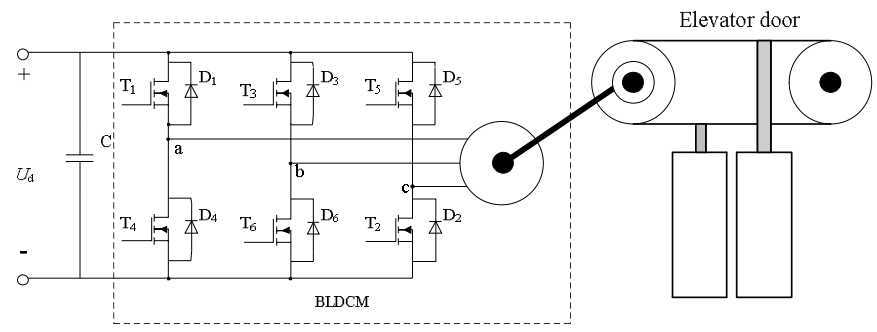

Fig. 1. Scheme of the brushless DC motor driving an elevator door.

Hence, the three line voltage equation under ideal condition can be calculated from Eq. 1 as

$$
\left[\begin{array}{l}
u_{a b} \\
u_{b c} \\
u_{c a}
\end{array}\right]=\left[\begin{array}{l}
u_{a}-u_{b} \\
u_{b}-u_{c} \\
u_{c}-u_{a}
\end{array}\right]=\left[\begin{array}{ccc}
R & -R & 0 \\
0 & R & -R \\
-R & 0 & R
\end{array}\right]\left[\begin{array}{l}
i_{a} \\
i_{b} \\
i_{c}
\end{array}\right]+\left[\begin{array}{ccc}
L-M & M-L & 0 \\
0 & L-M & M-L \\
M-L & 0 & L-M
\end{array}\right] \mathrm{p}\left[\begin{array}{l}
i_{a} \\
i_{b} \\
i_{c}
\end{array}\right]+\left[\begin{array}{l}
e_{a}-e_{b} \\
e_{b}-e_{c} \\
e_{c}-e_{a}
\end{array}\right]
$$

This model is useful in the control of brushless DC motors whether with or without hall sensors.

Fig. 2 shows the block diagram of the configuration of fuzzy control system for the brushless DC motor, which consists of two closed loops. The inner loop is the current hysteresis controller, which maintains the current at a certain level and ensures the stability of the servo system. The major advantage of the hysteretic controller is that it does not require the machine parameters to be known and presents fast load transient response ability. The commutations are obtained by comparing actual current $i_{\mathrm{a}, \mathrm{b}, \mathrm{c}}$ to a rectangular reference $i_{\mathrm{a}, \mathrm{b}, \mathrm{c}}$ and by keeping them in a hysteresis band $\Delta I_{\mathrm{b}}$.

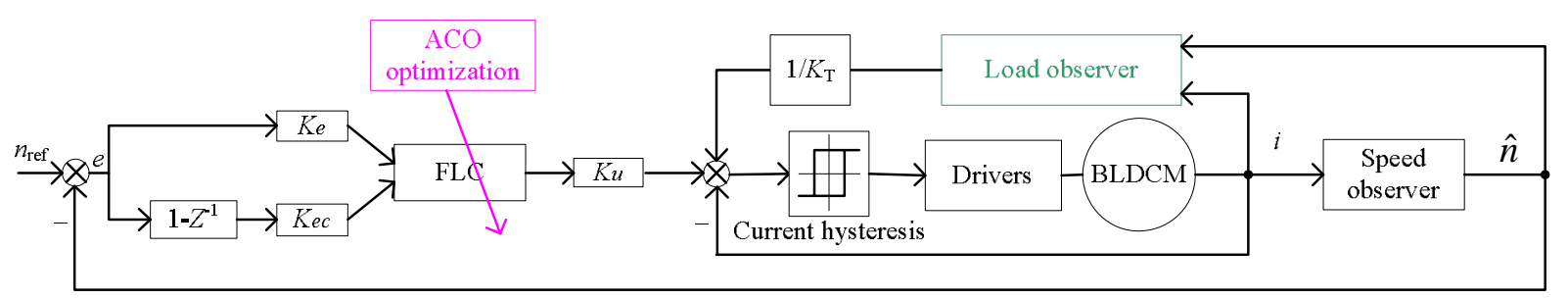

Fig. 2. Configuration of ACO based fuzzy control system for brushless DC motor.

The outer loop is designed to improve the static and dynamic characteristics of the brushless DC motor servo control system, where the fuzzy control is used. To make the fuzzy controller adapt to different operating conditions, the coefficients of the controller are tuned by the fuzzy rules automatically, which are optimized by the ACS algorithm. Also, the load observer for constant load and step load is built to enhance the robustness against disturbance of the proposed controller. For the zero-crossing points of the line back EMF $e_{\mathrm{AC}}, e_{\mathrm{BA}}$ and $e_{\mathrm{CB}}$ are exactly the commutation points of the motor, the line-line back-EMF based sensorless control are used in this paper. At zero speed, the rotor is initially placed in a known position by injecting a certain DC current. Then the motor is operating in open loop up to a given minimum speed where back EMF is reliable. At this point, a jump to line back EMF based sensorless control takes place.

\section{Design of ACO Based Fuzzy Controller}

Fuzzy Control. In Fig. 2, the speed error and its time derivative have been used as inputs of the fuzzy logic speed controller. These two input variables $e$ (speed error) and $e c$ (change in error) are calculated at each sampling period as

$$
\begin{aligned}
& e(k)=n^{*}(k)-n(k) \\
& e c(k)=e(k)-e(k-1)
\end{aligned}
$$

where $n^{*}(k)$ is the reference speed at sampling period $k$, and $n(k)$ is the actual estimated rotor speed at the same sampling period. 
Table 1 shows the fuzzy rules which are optimized through the ACO method. Through the optimization, 7 standard fuzzy sets are simplified as 5 fuzzy sets, and the standard 49 fuzzy rules are reduced to 25 rules including the 3 eliminated ones. When the corresponding rule of $R_{i}$ is eliminated, the input edge of the $R_{i}$ will be connected directly to the nodes which belong to the next rule $R_{i+1}$.

Table 1 The Linguistic Rules after ACO Optimization

\begin{tabular}{|c|c|c|c|c|c|}
\hline$E$ & & & & \\
\hline $\mathrm{PB}$ & $\mathrm{NB}$ & $\mathrm{NB}$ & $\mathrm{N}$ & $\mathrm{N}$ & $\mathrm{P}$ \\
\hline $\mathrm{P}$ & $\mathrm{NB}$ & $\mathrm{N}$ & $\mathrm{N}$ & $\mathrm{ZE}$ & $\mathrm{P}$ \\
\hline $\mathrm{ZE}$ & $\mathrm{NB}$ & $\mathrm{N}$ & $\mathrm{ZE}$ & $\mathrm{P}$ & $\mathrm{PB}$ \\
\hline $\mathrm{N}$ & $\mathrm{N}$ & $\mathrm{ZE}$ & $\mathrm{P}$ & $\mathrm{ZE}$ & $\mathrm{P}$ \\
\hline $\mathrm{NB}$ & $\mathrm{NB}$ & $\mathrm{PS}$ & $\mathrm{P}$ & $\mathrm{P}$ & $\mathrm{PB}$ \\
\hline
\end{tabular}

Load observer. Considering the variable and unknown load torque, the inertia and friction coefficient in the elevator door motor control system are presented as

$$
J=J_{0}+\Delta J, B_{\mathrm{v}}=B_{\mathrm{v} 0}+\Delta B_{\mathrm{V}}
$$

where $J_{0}$ and $B_{\mathrm{v} 0}$ is the nominal value of $J$ and $B_{\mathrm{v}}$ respectively.

Thus the mechanical equation of the brushless DC motor can be obtained as

$$
\begin{aligned}
& \frac{\mathrm{d} \Omega}{\mathrm{d} t}=K_{T} i-\frac{B_{\mathrm{v} 0}}{J_{0}} \Omega-\frac{K_{T}}{J_{0}} T_{d} \\
& T_{d}=\Delta J \frac{\mathrm{d} \Omega}{\mathrm{d} t}+\Delta B_{\mathrm{v}} \Omega+T_{\mathrm{L}}
\end{aligned}
$$

where $T_{\mathrm{d}}$ is the unknown load disturb torque.

Thus, the observer can be applied for the control of an elevator door, which can be expressed as

$$
\begin{gathered}
\hat{\mathbb{W}}_{3}=\frac{L_{1}}{J_{0}} \hat{x}_{12}+\frac{L_{1}}{J_{0}} B_{\mathrm{v} 0} x_{11}-K_{T} L_{1} u_{1} \\
x_{13}=\hat{x}_{12}-L_{1} x_{11}
\end{gathered}
$$

where $\hat{x}_{12}=\hat{T}_{d}, x_{11}=\Omega, u_{1}=i$, and $L_{1}$ is the observer gain with a value of -0.0157 .

\section{Experimental results}

This system is applied to the elevator door control. A trapezoid curve is used as the speed reference to simulate the speed-distance characteristic.

In order to further test the effectiveness of the proposed control scheme, the new ACO based fuzzy controller is implemented by using TI's TMS320LF2407A DSP. The execution time of the DSP to perform all the control actions and calculations is about $60 \mu \mathrm{s}$. The memory requirement for the offline lookup table is $10 \mathrm{~KB}$. Fig. 3 shows the experimental results of the motor speed step response for the new ACO based fuzzy controller, when the reference speed is set to $500 \mathrm{r} / \mathrm{min}$ and $3000 \mathrm{r} / \mathrm{min}$ respectively. In contrast to the results in [7], Fig. 3 shows that the new proposed controller provides a 
less overshoot and a better response capability. Fig. 4 depicts the corresponding steady-state waveform of the line voltages $U_{\mathrm{AB}}$ and $U_{\mathrm{AC}}$. The working conditions for motor are $n^{*}=500 \mathrm{r} / \mathrm{min}, T_{\mathrm{L}}=0.4 \mathrm{~N} \cdot \mathrm{m}$ and $n^{*}=3000 \mathrm{r} / \mathrm{min}, T_{\mathrm{L}}=0.4 \mathrm{~N} \cdot \mathrm{m}$ respectively in Fig. 3(a), Fig. 4(a) and Fig. 3(b), Fig. 4(b)

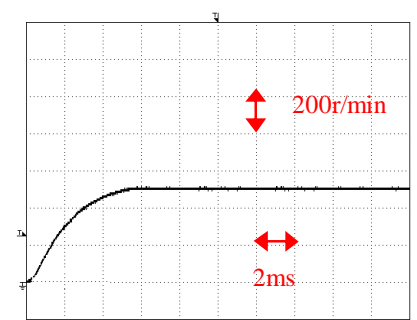

(a)

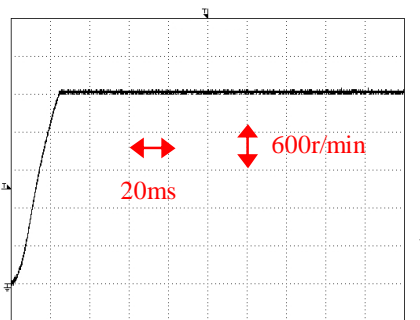

(b)

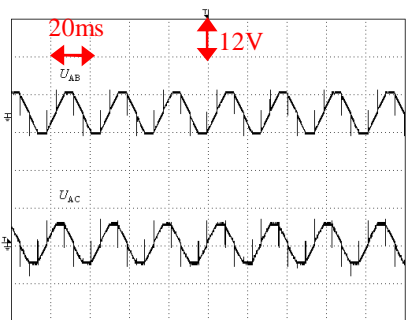

(a)

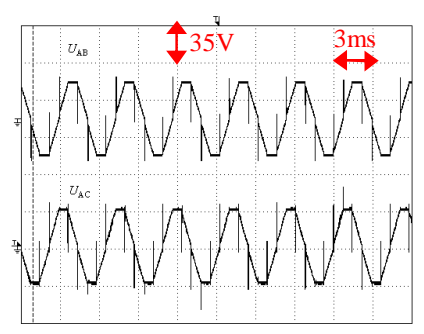

(b)

Fig. 3. Experimental step speed response curves.

\section{Conclusion}

This paper has proposed an ACO based fuzzy controller to the brushless DC motor servo system. The fuzzy rules are optimized offline, while the parameters of the fuzzy controller are tuned online. The membership functions of the controller have been optimized by the ACS algorithm. Combined with the linear load observer, the comprehensive performance is enhanced. Its adaptability has been verified by the experimental results.

\section{Acknowledgment}

This work was supported by a grant from National Natural Science Foundation of China (No. 51577124), Tianjin Research Program of Application Foundation and Advanced Technology (No. 11JCYBJC07900, No.15JCZDJC32100) and National Training Program of Innovation and Entrepreneurship for Undergraduates of Tianjin University (No. 201510056031).

\section{References}

[1] J. X. Shen, and S. Iwasaki, Sensorless control of ultrahigh-speed PM brushless motor using PLL and third harmonic back EMF, IEEE Transactions on Industrial Electronics, vol. 53, no. 2, pp. 421-428, April 2006.

[2] M. J. Yang, H. L. Jhou, B. Y. Ma, and K. K. Shyu, A cost-effective method of electric brake with energy regeneration for electric vehicles, IEEE Transactions on Industrial Electronics, vol. 56, no. 6, pp. 2203-2212, June 2009.

[3] Y. Liu, Z. Q. Zhu, and D. Howe, Direct torque control of brushless DC drives with reduced torque ripple, IEEE Transactions on Industry Application, vol. 41, no. 2, pp. 599-608, March 2005.

[4] F. Rodriguez and A. Emadi, A novel digital control technique for brushless DC motor drives, IEEE Transactions on Industrial Electronics, vol. 54, no. 5, pp. 2365-2373, October 2007.

[5] C. L. Xia, P. J. Guo, T. N. Shi, and M. C. Wang, Speed control of brushless DC motor using genetic algorithm based fuzzy controller, Proceedings of the CSEE, vol. 25, no.11, pp. 129-133, November 2005.

[6] F. J. Lin, P. K. Huang, and W. D. Chou, Recurrent-fuzzy-neural- network-controlled linear induction motor servo drive using genetic algorithms, IEEE Transactions on Industrial Electronics, vol. 54, no. 3, pp. 1449-1461, June 2007.

[7] C. L. Xia, H. W. Fang, W. Chen, and et al, Ant colony algorithm based fuzzy control for a brushless DC motor, The Sixth World Congress on Intelligent Control and Automation, Dalian, 2006, pp. 6498-6502. 